\title{
Flexural Strength of Concrete Beams Containing Twinned Coconut Fibers
}

\author{
WILSON O. TABLAN \\ wiltab_59@yahoo.com \\ Liceo de Cagayan University
}

Date Submitted: July 6, 2007

Final Revision Accepted: October 30, 2007

\begin{abstract}
The study examined the effect of twined coconut fibers as reinforcement to concrete beams on its flexural strength and cracking behavior. For treatment, 25\% twined coconut fibers were added as reinforcement. The ratio of 1:2:4 mixture of concrete was used in making the specimens and a curing period of twenty-eight days was observed. The results showed that the concrete beams reinforced with twined coconut fibers yielded a higher flexural strength compared to concrete beams without coconut fiber reinforcement. Moreover, concrete beams with twined coconut fibers indicated transformation from abrupt to gradual failure of the specimens and splitting when ultimate load was applied. Hence, the added twined coconut fibers enhanced the flexural strength of the concrete beams.

Key words- Twinned coconut fibers, Concrete mix, Flexural strength, Concrete beams.
\end{abstract}

\section{INTRODUCTION}

Flexural strength is of special importance in spite of its low magnitude as compared to compressive strength. It is most commonly utilized in beams and slabs (Gambhir 1995) . Flexural loads, temperature change, uneven shrinkage, and moisture change cause undue stresses (Herubin 1977). Plain concrete is inherently weak in tension and has limited ductility and little resistance to cracking. Micro cracks are always present in concrete ( Siddique 1997). Because of its low tensile strength, the cracks propagate 
with the application of load. In general, concrete members are provided with steel reinforcement because of the latter's high modulus of elasticity and tensile strength. A reinforcement material with high modulus of elasticity is capable of imparting additional stiffness to the concrete, resulting to an increased cracking strength (Santha \& Santha 1999).

Today, the use of coconut fibers (coir) has become very common among professionals in various industries due to its versatility. In the horticulture industry, agricultural industry, erosion control industry or construction industry for nonstructural members, coir has established a remarkable reputation for its superiority to other available natural materials. The processed coconut fibers are light in weight, strong, and elastic. They are resistant to abrasion and seawater. They have extremely low decomposition rate and have high strength compared to other natural fibers. According to Balaguru and Shah (1994), coconut fibers have an ultimate strength of 120-200 $\mathrm{MPa}$ and an elongation at break of $10-25 \%$ of the length.

The study on the variability in flexural strength has been lagging behind. It is clear, however, that the flexural strength has a relatively greater fluctuation than compressive strength (Montgomery 1991). The failure of the plain concrete beam in bending test is controlled by the tensile strength of the concrete. The propagation of microcracks has an important role in this respect. A simplified explanation is that as soon as the tensile stress reaches a maximum value in the bottom fiber of the beam in which the section cannot resist cracking, failure occurs (Gram 1989). It is a well-established fact that, in most cases, the failure of concrete under load takes place through progressive, rather than abrupt, internal cracking starting in the matrix portion.

The incorporation of small steel fibers to the plain concrete beam increases its local tensile strength, thus increasing the concrete bean's flexural strength. The fibers trap cracks and reduce or delay their spread. In other words, the addition of fibers to plain concrete beam converts the abrupt failure in bending into a gradual failure (Castro \& Naaman 1981). It is assumed that the flexural strength and cracking behavior of the concrete beams would be affected by the addition of twined coconut fibers.

\section{OBJECTIVES OF THE STUDY}

As generally observed, natural fibers can be used as reinforcement in cementbased composites to produce low-cost housing elements. Moreover, fiber-reinforced board costs lesser as compared to commercial board, but offers higher strength and ductility and toughness (Sera, 1990). This study was conducted to determine whether the twined coconut fibers, when added to concrete mix, would improve the flexural strength of the concrete beam. Likewise, this study also aimed to find out if twined coconut fiber would help in minimizing cracks due to load applications. 


\section{MATERIALS AND METHODS}

\section{Test specimen}

The cement composites for testing were prepared in the form of rectangular beams, $150 \mathrm{~mm} \times 150 \mathrm{~mm} \times 535 \mathrm{~mm}$, as described in ASTM C 78-84 for the determination of the standard control flexural strength. Twenty specimens of ten replicas of plain cement composites and ten replicas of $0.25 \%$ by weight of the aggregates of coconut fibers were made and tested. For each batch mixed, the slump test was conducted to measure the workability in accordance with ASTM C 143-78 (Slump of Portland Cement Concrete). The curing time of all specimens was 28 days before laboratory testing was performed.

Specimens were cured in accordance with ASTM C 31-84, the standard method of making and curing concrete test specimen in the field. The Third-Point Loading Method (ASTM C 78-84) was used for testing. The loading rate to failure applied to the specimen was $5 \mathrm{kN} / \mathrm{sec}$.

\section{Preparation of Test Specimens}

The aggregates were dried for five days to ensure a Saturated Surface Dry (SSD) condition before using them.

Weighted Ratio of Concrete Mix: 1:2:4

$\begin{array}{lllll}\text { Cement } & : & 40 \mathrm{~kg} & \\ \text { Sand } & : & 80 \mathrm{~kg} & \\ \text { Gravel } & : & 160 \mathrm{~kg} & & \\ \text { Water } & : & 40 \mathrm{kgxO} .48 \quad= & 19.2 \mathrm{~kg}\end{array}$

\section{Computation:}

Absolute Volume of Materials $=$ weight I unit weight

$\begin{array}{lll}\text { Cement: } 4013.15 & = & 12.698 \text { L or } 0.012698 \mathrm{~mm} 3 \\ \text { Sand }: 80 / 2.64= & 30.303 \mathrm{~L} \text { or } 0.030303 \mathrm{~m} 3 \\ \text { Gravel : } 160 / 2.68=59.702 \text { L or } 0.059702 \mathrm{~m} 3 \\ \text { Water : } 19.2 / 1.0=19.2 \text { LorO.0192m3 }\end{array}$

Total Absolute Volume of Materials $=121.903 \mathrm{~L}$ or $0.121903 \mathrm{~m} 3$.

Volume of Mold: $150 \mathrm{~mm}$ x 150mm x 535mm =12,037,500 mm3 or $0.010375 \mathrm{~m} 3$

Total Volume of Molds: 0.010375 m3 x 100.10375 m3.

Volume of Materials for every Mixture:

Volume of Matenals $=$ Weight $\mathrm{x}$ total volume of molds

Total absolute volume of materials

Using 180\% water absorption by weight of coconut fibers (FCR Publication, 1987) 
and 0.48 water-cement ratio:

Water Absorbed: Weight of Fiber x 180\% water absorption:

Plain Concrete Mixture:

$\begin{array}{lll}\text { Cement } & : & 40 \mathrm{~kg} \times 0.10375 \mathrm{~m} 3 / 0.121903 \mathrm{~m} 3=34.043 \mathrm{~kg} \\ \text { Sand } & : & 34.043 \mathrm{~kg} \times 268.086 \mathrm{~kg} \\ \text { Gravel } & : & 34.043 \mathrm{~kg} \times 4=136.172 \mathrm{~kg} \\ \text { Water } & : & 19.2 \mathrm{kgxo} .10375 / 0.121903=16.341 \mathrm{~kg}\end{array}$

Concrete with $0.25 \%$ Coconut Fibers Mixture:

Cement : $\quad 34.043 \mathrm{~kg}$

Fiber $\quad$ : $\quad \%$ fiber $\times($ wt. of sand + wt. of gravel from

Mixture A).

$0.25 \% \times(68.086+136.172)=5.126 \mathrm{~kg}$

$\begin{array}{lll}\text { Sand } & : & 68.086 \mathrm{~kg} \\ \text { Gravel } & : & 136.172 \mathrm{~kg} \\ \text { Water } & : & 16.341 \mathrm{~kg}\end{array}$

The experimental method used in this study was the comparison between control specimens (without treatment) and the experimental specimens with treatment with ten replications each. The dependent variable in the experiment was the flexural strength while the independent variable was the percentage of twined coconut fibers by weight of aggregates. The data gathered from the experiment were analyzed using t-test at $5 \%$ level of significance. This method was further used to compare the sets of specimens and to find out if there was a significant difference between their means.

Hypothesis:

Ho: The use of twined coconut fibers as a concrete reinforcement does not have any significant effect on the concrete beam's flexural strength. That is: $\mu c=\mu \mathrm{T}$.

\section{RESULTS AND DISCUSSION}

\section{The Ultimate Load Data}

Table 4.1 shows the ultimate load carried by each specimen.

Table 4.1. Ultimate load carried by each specimen, $k N$.

\begin{tabular}{|c|c|c|c|c|c|c|c|c|c|c|}
\hline \multirow{2}{*}{$\begin{array}{l}\text { Specimen } \\
\text { Control }\end{array}$} & \multicolumn{10}{|c|}{ Ultimate load, kN } \\
\hline & 16.7 & 17.5 & 18.8 & 17.6 & 13.2 & 13.4 & 19.2 & 17.4 & 15.6 & 15.2 \\
\hline Treatment & 18.7 & 17.6 & 23.3 & 27.0 & 23.3 & 16.5 & 27.0 & 21.2 & 21.4 & 17.4 \\
\hline
\end{tabular}


Ten replicas for plain cement composites and ten replicas for cement composites with $0: 25 \%$ twined coconut fibers as reinforcement were tested. A total of twenty specimens were produced. The results revealed that the specimens without coconut fibers splitted abruptly into two after while the specimens with $0.25 \%$ twined coconut fibers did not split but cracked slowly. The twined coconut fibers controlled the cracking and splitting of the specimens.

\section{Computed Flexural Strength Data}

The flexural strength of each specimen was computed using the third-point loading method based on the formula in ASTM C 78-84:

$\mathrm{f}=\mathrm{PL} / \mathrm{bd} 2$

Where: $\mathrm{f}-$ flexural strength

$\mathrm{P}$ - dead load + ultimate load of the specimen

$\mathrm{L}$ - effective length of the span, $450 \mathrm{~mm}$

B - width of the specimen, $150 \mathrm{~mm}$

$\mathrm{D}$ - depth of the specimen,15Omm.

Table 4.2. Computed flexural strength, $M P a$.

\begin{tabular}{|c|c|c|c|c|c|c|c|c|c|c|}
\hline Specimen & & & & & Ultim & load, kl & & & & \\
\hline Control & 2.227 & 2.333 & 2.507 & 2.347 & 1.760 & 2.560 & 2.320 & 2.080 & 2.027 & 2.227 \\
\hline Treatment & 2.493 & 2.347 & 3.107 & 3.600 & 3.107 & 2.200 & 3.600 & 2.827 & 2.853 & 2.320 \\
\hline
\end{tabular}

The computed results of the flexural strength of every specimen using the threepoint loading equation are in Table 4.2. The variations of the computed flexural strength of the two sets of specimens were perhaps due to the manual compaction of fresh concrete.

\section{Statistical Analysis Using T-test}

Table 4.3 Descriptive statistics of computed flexural strength

\begin{tabular}{|c|c|c|c|c|c|c|}
\hline \multicolumn{7}{|c|}{ Descriptive Statistics: Control, Treatment } \\
\hline Variable & $\mathrm{N}$ & Mean & Median & IrMean & stDey & SE Mean \\
\hline Control & 10 & 16.790 & 17.050 & 16.937 & 1.771 & 0.560 \\
\hline Treatmen & 10 & 21.34 & 21.30 & 21.24 & 3.83 & 1.21 \\
\hline Variable & Minimum & Maximum & Q1 & 23 & & \\
\hline Control & 13.200 & 19.200 & 15.500 & 17.900 & & \\
\hline Treatmen & 16.50 & 27.00 & 17.55 & 24.23 & & \\
\hline
\end{tabular}

Table 4.3 shows the corresponding values of the descriptive statistics of the computed flexural strength. As shown, the mean of the control set was 16.790 while that of the experimental set result reveals a difference in flexural strength for about $25 \%$. It also reveals that the dispersion of the data for the control set was smaller than 
Liceo Journal of Higher Education Research

of the experimental set as indicated by standard deviation.

Figures 4.1 and 4.2 below show the normality test of the computed flexural strength

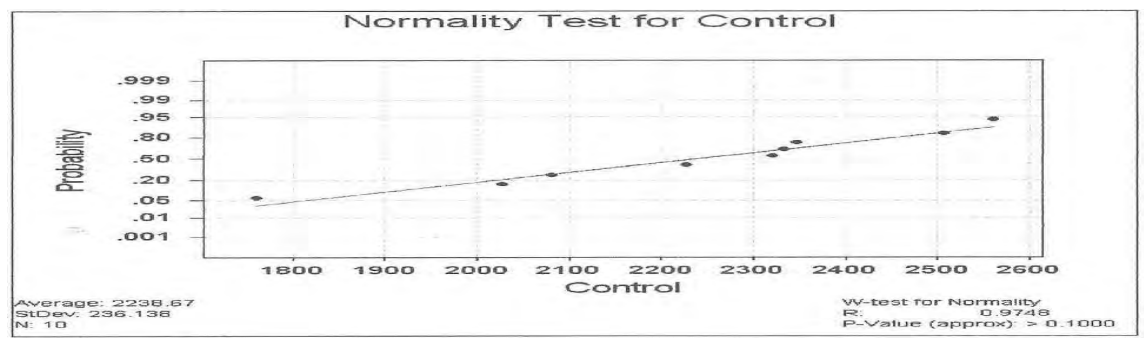

Figure 4.2. Normality test for treatment

The normality test for control and experimental sets shows that the flexural strength data were normally distributed as evidenced by the Ryan-Joiner Normality Test. The R values of 0.9748 (control) and 0.9780 (experimental) were obtained. Table 4.4 shows the results of the analysis using t-test of the computed flexural strength.

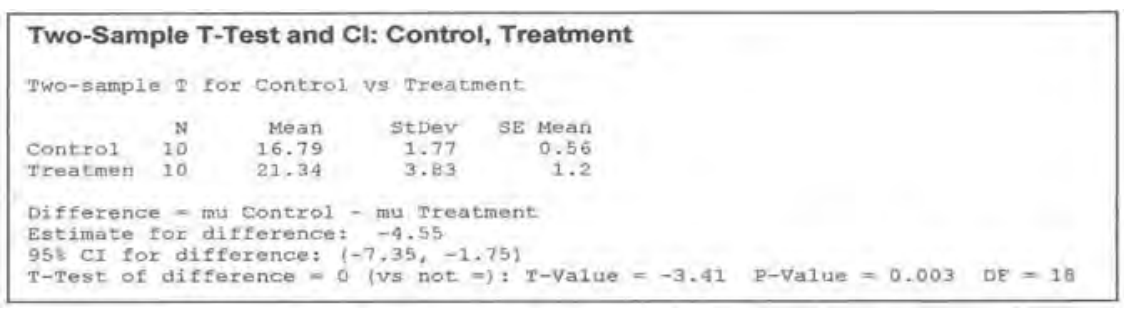

Table 4.4. Statistical analysis using t-test.

The statistical analysis shows a T-Value of the Two-Sample t-test was -3.41 and a P-Value $=0.003<0.05$. Therefore, there was a significant difference in flexural strength between the control and experimental specimens at 0.05 level of significance. Hence, the hypothesis was rejected.

\section{CONCLUSIONS}

The flexural strength of the concrete beam is significantly affected by mixing twined coconut fibers

Adding coconut fibers into the mixture gives a $25 \%$ additional flexural strength to plain concrete.

The presence of coconut fibers as concrete reinforcement minimizes cracking and controls abrupt failure and splitting of the concrete. 


\section{LITERATURE CITED}

Balaguru, P. N. and Sha, S. P., (1992). Fiber reinforced cement composites, Singapore, McGrawhill, Inc., pp. 20-23, 105.

Balaguru, P. N., May-Jun (1994). “Contribution of fibers to crack reduction of cement composites during initial and final setting period", ACI Materials Journal, Vol. 91, No. 3, pp 280-288.

Castro, J. and Naaman, A. E., (1981). “Cement mortar reinforced with natural fibers". Journal of Ferrocement, Vol.11, No. 4, pp. 285-301.

Gambhir, M. L., (1995). Concrete technology, New Delhi, Tata McGrawhill Publishing Company, Second Edition, pp. 204-2 15.

Gram, H. E., (1989). "FCR and MCR - concrete roofing tiles with or without fibres", FCR-News, FAS-Fibre Concrete Roofing Advisory. 5: 3-9.

Herubin, M. T., (1977). Basic construction materials, methods and testing, 3rd Edition, New Jersey: Prentice Hall Inc., pp. 31-39.

Montgomery, D. C., (1991) Design and analysis of experiments, New York, John Wiley and Sons, 3rd Edition.

Santha and Santha, (1999) Facts on coir: lessons from the past, Rolanka international, Inc., 365 Toccoa Place, Jonesboro GA 30236

Sera, B. E., (1990). "Natural fibers as reinforcement". Journal of Ferrocement, Vol. 20, No. 2, pp. 109-124.

Siddique, R., (1997). Concrete beams reinforced with twines of natural fibers", Journal of Ferrocement, Vol. 27, No. 2, pp. 119-125. 